\title{
The Economic Cost of Treatment-Resistant Depression in Patients Referred to a
}

\author{
Specialist Service
}

Paul McCrone, King's Health Economics, Health Services and Population Research Department, Institute of Psychiatry, Psychology and Neuroscience, King's College London, London, UK

Felicitas Rost, Portman Clinic, Tavistock and Portman NHS Foundation Trust, London, UK

Leonardo Koeser, King's Health Economics, Health Services and Population Research Department, Institute of Psychiatry, Psychology and Neuroscience, King's College London,, London, UK

Iakovina Koutoufa, Research Department of Clinical, Educational and Health Psychology, University College London, UK

Stephanie Stephanou, Tavistock Clinic, Tavistock and Portman NHS Foundation Trust, London, UK stephanie.stephanou.10@gmail.com

Martin Knapp, Personal Social Services Research Unit, London School of Economics and Political Science, London, UK

David Goldberg, Institute of Psychiatry, Psychology and Neuroscience, King's College London, London, UK

David Taylor, Tavistock Clinic, Tavistock and Portman NHS Foundation Trust, London, UK

Peter Fonagy, Research Department of Clinical, Educational and Health Psychology, University College London, UK

\section{Authors' Contributions}

PM, FR, LK \& DT each contributed to writing this paper. FR, IK and SS were responsible for data collection and preparation for analysis. PM and LK carried out the statistical analyses. PF, MK \& DG were responsible for the concept and design of the study. PF is the TADS Principle Investigator and has overall responsibility for its research management. All authors read and approved the final manuscript.

\section{Funding sources}

This research was funded by the Tavistock Clinic Charitable Foundation and the Tavistock \& Portman NHS Foundation Trust. PF is supported by a National Institute for Health Research 
Running Head: Economic Cost of TRD

(NIHR) Senior Investigator Award [grant number NF-SI-0514-10157]. PF was in part supported by the NIHR Collaboration for Leadership in Applied Health Research and Care (CLAHRC) North Thames at Barts Health NHS Trust. The views expressed are those of the authors and not necessarily those of the NHS, the NIHR or the Department of Health.

\section{Acknowledgements}

We would like to acknowledge and thank Hannah Ridsdale, Jenny Hedley, Lauren Whitelaw, Naomi Law, Rebecca Johnson, Siri Steinmo, and Zoe Tweedale for data collection and preparation for analysis.

Word lengths of the paper: 3093 (excluding references)

Correspondence concerning this article should be addressed to:

Dr Felicitas Rost, Tavistock and Portman NHS Foundation Trust, Portman Clinic, 8 Fitzjohn's Avenue, London NW3 5NA, United Kingdom. Tel: +44 (0) 20 89382234, Email: frost@tavi-port.nhs.uk 
Running Head: Economic Cost of TRD

\begin{abstract}
Background: Patients with treatment-resistant depression (TRD) suffer very significant morbidity and are at a disadvantage concerning optimal clinical management. There are high associated societal costs.
\end{abstract}

Aims: A detailed analysis of health economic costs in the United Kingdom in a group manifesting a severe form of TRD in the 12 months before their participation in a major randomized controlled treatment trial.

Methods: The sample consisted of 118 participants from the Tavistock Adult Depression Study. Recruitment was from primary care on the basis of current major depression disorder of at least 2 years' duration and two failed treatment attempts. Service utilization was assessed based on self-report and general practitioner (GP) medical records. Generalized linear models were used to identify predictors of cost. Results: All participants used GP services. Use of other doctors and practice nurses was also high. The mean total societal cost was $£ 22,124,80 \%$ of which was due to lost work and care required of families. Level of general functioning was found to be the most consistent predictor of costs.

Conclusions: Severe forms of TRD are associated with high costs in which unpaid care and lost work predominate. Treatments that improve functioning may reduce the large degree of burden. 
Running Head: Economic Cost of TRD

\section{Introduction}

Currently, depression is estimated to affect approximately 121 million people worldwide and is associated with approximately 850,000 deaths by suicide every year. It is the leading cause of disability and is expected to be the second leading contributor to the global disease burden by 2020 (Demyttenaere et al., 2004; WHO, 2010). Key costs of depression include treatment costs and the costs associated with family care and lost employment. The economic burden of major depressive disorder (MDD) was estimated at $\$ 124$ billion in the USA in 2012 (Mrazek et al., 2014) and $€ 118$ billion in Europe in 2004 (Richards, 2011). In England, in 2007, the total cost of services for depression was estimated to be in the region of $£ 1.7$ billion; adding lost employment increased this by a further $£ 5.8$ billion (McCrone et al., 2008). Between $10 \%$ and $20 \%$ of patients with a major depressive episode (Kessler et al., 2003; Kubitz et al., 2013) will go on to suffer more complex and protracted forms of depression, with poor responses to treatment and major effects on work functioning, interpersonal relationships, and quality of life (Greden, 2001). These forms are frequently termed treatment-refractory or treatment-resistant depression (TRD). However, while there appears to be a general consensus on the definition of chronic depression (a minimum

of a 2-year period), there are inconsistencies surrounding the definition of TRD (Berlim \& Turecki, 2007). These inconsistencies make it difficult to discern its actual prevalence. High rates of non-response of depressed patients to treatments in general have been reported (Simon et al., 2002; Thomas et al., 2013), with 12-20\% of depressed patients not benefiting even from multiple courses of treatment (Kubitz et al., 2013). These patients have also been found to make a disproportionate contribution to the economic burden associated with the spectrum of depressive disorders (Crown et al., 2002; Ivanova et al., 2010). For example, studies suggest that compared with patients 
Running Head: Economic Cost of TRD

suffering from chronic depression, patients with TRD have significantly higher costs for imaging tests, physician visits and psychiatric hospitalization (Fostick et al., 2010), as well as for direct medical expenditures (Olchanski et al., 2013).

The aim of this study is to investigate the costs associated with this patient group in the United Kingdom (UK). The sample consisted of participants from the Tavistock Adult Depression Study (TADS; Fonagy et al., 2015), who were referred from primary care with a diagnosis of MDD of at least 2 years' duration and at least two failed treatment attempts. Specifically, we aimed: (i) to measure service use and lost employment and their associated costs over the 1-year period before randomization into the study; and (ii) to identify any particular clinical and demographic characteristics associated with these costs.

\section{Method}

\section{Data and study design}

This study was a retrospective analysis of service use and costs of the participants recruited to the TADS. The TADS was a pragmatic randomized controlled trial set up to investigate the effectiveness of long-term psychoanalytic psychotherapy (LTPP) compared with treatment as usual (TAU) delivered according to UK national guidelines as arranged by the participants' primary care providers. Detailed descriptions of the study design and outcome findings are available elsewhere (Fonagy et al., 2015; Taylor et al., 2012). In brief, participants were recruited from GP practices from central and north London from February 2002 to May 2009. Patients were eligible if they were aged over 18; had a current diagnosis of MDD as assessed by the Structured Clinical Interview for DSM-IV (SCID-I; First et al., 2001); reported a minimum duration of 2 years of the current depressive episode; scored a minimum of 14 on the 17 -item version 
Running Head: Economic Cost of TRD

of the Hamilton Rating Scale for Depression (HRSD; Hamilton, 1967) and 21 on the Beck Depression Inventory (BDI-II; Beck et al., 1996); and had at least two failed treatment attempts, one of which must have included an antidepressant medication (ADM), while the other could include either an ADM from a different class or a psychological therapy. Patients with a diagnosis of psychotic disorder, bipolar disorder, psychiatric input for substance abuse or dependency, mild or severe learning disability, and evidence of organic brain disorder were excluded. Ethical approval was sought and approved by the Institutional Review Board of the NHS West Midlands Research Ethics Committee (MREC02/07/035).

\section{Service use and cost}

Participants recruited into the trial $(\mathrm{n}=129)$ completed an adapted version of the Client Service Receipt Inventory (CSRI; Beecham \& Knapp, 2001) as part of a comprehensive assessment, and consented to the study accessing their GP medical records. The information in the CSRI was provided by the participants and covered the 12-month period before randomization into the trial. Information collected included: number and duration of contacts with primary and secondary health and social care services; unpaid informal care received, such as help with child care, personal care, help in and around the home, and help outside the home; employment status; and days of lost employment. The same information was also extracted from the participant's medical records by two independent researchers. To achieve reliability of data extraction, a third researcher clarified any discrepancies and an average was calculated in cases of a confirmed major difference. For the current analysis, both data sources were combined. A societal perspective was adopted in which both costs to the health and social care system and the broader impacts on productivity and families were included. Service use data were combined with nationally representative information on unit costs. For most services these unit costs were drawn from an annually updated source (Curtis, 2010). Hospital costs were obtained from routine data collected by the UK Department of Health (Department of Health, 2011). For the cost of informal care we used an average hourly wage rate of $£ 14.60$; lost employment costs were calculated using an average daily wage rate of $£ 97.52$ (Office for National Statistics, 2011). 
Running Head: Economic Cost of TRD

\section{Data analysis}

Analyses were conducted on all cases providing service use data. These were baseline $\underline{\text { data and so no imputation for missing cases was conducted. However, where quantities }}$ of specific service use was missing we used median values for others using that services. Descriptive statistics were produced for socio-demographic characteristics; length and severity of depression; functioning, as measured with the Global Assessment of Functioning Scale (GAF; Hilsenroth et al., 2000); and Generalized Anxiety Disorder (GAD), as measured with the SCID-I (First et al., 2001), coded here as a binary variable comparing moderate or severe versus mild or no levels. The number and percentage of participants using specific services is reported and the mean number and standard deviation (SD) of contacts by those who used them, as well as the mean and SD cost for the whole sample (i.e. including those not using specific services). Univariate descriptive analyses were conducted to observe the relationship between demographic and clinical characteristics and cost categories (healthcare, informal care plus lost employment, and total cost). This was followed by regression analyses using the same variables and cost categories, using Stata version 11. As costs tend to follow a skewed distribution, we used generalized linear models with a gamma family and log link function (Mihaylova et al., 2011) in order to identify cost predictors. This was due to the positively skewed cost distribution. In these exploratory analyses statistical significance was assumed at the $\mathrm{P}<0.1$ level.

\section{Results}

\section{Characteristics of the sample}


Running Head: Economic Cost of TRD

Of the 129 participants randomized into the study, health economic data were available for $118(91.5 \%)$. Table 1 provides a summary of their socio-demographic and diagnostic characteristics. As per protocol, all patients had a diagnosis of current MDD; $76 \%$ had an additional diagnosis of early-onset dysthymia and $37 \%$ had a comorbid diagnosis of GAD (13\% mild and $25 \%$ moderate/severe levels). The average total duration of depression was 25.4 years $(\mathrm{SD}=12.42)$ and the average length of the current depressive episode was 3.7 years $(\mathrm{SD}=3.01)$. In terms of depression severity, $75 \%$ scored within the severe range on the BDI-II (mean=36.2, SD=9.8) and $64 \%$ within the severe-very severe range on the HRSD-17 (mean=21.4, $\mathrm{SD}=5.6$ ). The mean GAF score was 48.7 ( $\mathrm{SD}=7.6)$ indicating serious functional impairment. The characteristics of the 118 participants for whom we obtained cost data were very similar to those of the 129 participants comprising the full sample (details available from the authors).

\section{Insert Table 1 about here}

\section{Service use and costs}

Table 2 shows the number of the sample using specific services and, for those who had use, how many times on average this occurred. Costs are also shown for the whole sample. Only a small number of participants had been psychiatric inpatients in the 12 months before joining the trial(see Table 2); however, one in six had had hospital admissions for physical health problems. All patients reported having had GP contacts: their average frequency was slightly less than one per month. More than two-thirds of the sample had practice nurse contacts; a similar number had outpatient contacts for physical health problems. Nearly half the sample reported receiving informal care from family/friends in the previous 12 months due to their health problems. Two-thirds of 
Running Head: Economic Cost of TRD

participants had had lost employment due to health problems (either days off sick or out of work).

\section{Insert Table 2 about here}

The services with the highest mean costs were inpatient care, outpatient visits, day hospital attendances and GP contacts. Together, they accounted for $70 \%$ of the total average healthcare cost of $£ 4388$ ( $\mathrm{SD}=£ 7347)$. However, informal care from family/friends was responsible for a higher proportion of the costs than those of health and social care services, and lost employment in particular was responsible for over twice the amount for health and social care. These social and employment categories accounted for $26 \%$ and $54 \%$, respectively, of the total mean cost of $£ 22,124$ (SD = $£ 23,466)$.

Health and social care services costs were somewhat higher for women than for men; this gender difference held for informal care and lost employment costs as well (see Table 3). Participants in the 41-50 and 51-60 age groups had the highest health and social care costs. Costs were also higher for married/cohabiting participants and those of non-white ethnicity. Costs associated with informal care and lost employment were highest for those aged 31-40. Overall costs were highest for participants who were unemployed. Participants with higher baseline depression severity had higher costs than those whose depression was less severe. Better functioning, as measured with the GAF, was associated with lower formal health and social care costs; the association between GAF and the costs of informal care and lost employment was less clear.

\section{Insert Table 3 about here}

Table 4 shows the results of the regression analysis of costs against the independent variables of gender, age, relationship status, ethnicity, depression severity, and 
Running Head: Economic Cost of TRD

functioning (GAF). After controlling for other characteristics, participants aged 51-60 were shown to have health and social care costs that were on average $140 \%$ higher than those aged 19-30. Higher GAF scores (i.e. indicating better function) were associated with lower health and social care costs: a one-unit increase in the GAF was associated with a $3 \%$ reduction in costs. The costs associated with informal care and lost employment of participants aged 31-40 were significantly higher than those aged 1930. Married/cohabiting participants had higher costs than those who were single, widowed, or divorced. If baseline depression severity scored 40 or above on the BDI-II then informal care and lost employment costs were significantly increased. Again, the GAF score was inversely related to cost. Total costs were positively related to those aged 31-40, 41-50 and 51-60, participants who were married/cohabiting and those from a non-white ethnic group.

\section{Insert Table 4 about here}

\section{Discussion}

This study measured the service use and costs over a 1-year period for patients with severe and complex forms of depression, commonly referred to as TRD. We found that the mean annual cost for individuals in this patient group in $2009 / 10$ prices was high, at $£ 22,124$. This is comparable to the costs associated with dementia and schizophrenia (McCrone et al., 2008). In current (2015/16) prices the figure would be approximately $£ 25,000$. Our figures are at least seven times as high as those reported by another recent UK study evaluating costs in a sample of patients suffering from TRD using a societal perspective (Hollinghurst et al., 2014). However, differences in the definition of TRD indicate that the sample in that study was less severely affected than ours. This difference emphasizes the need for precision in terms of defining the characteristics of 
Running Head: Economic Cost of TRD

these patients and the importance of establishing a commonly accepted definition of TRD.

The prevalence of depressive episodes in the general adult population of England has been reported to be $2.3 \%$ (McManus et al., 2009), indicating that in 2016 the total number of individuals with depression in England was estimated to be 1.3 million (McCrone et al., 2008). Epidemiological studies in the UK, like those of other countries (see Bromet et al., 2011), reveal that in many patients depression does not remit completely. Studies of the natural course of depression generally find that half of patients will still meet diagnostic criteria after a year (Simon et al., 2002). This corresponds to the sample whose costs were evaluated in the study of Hollinghurst et al. (2014). However, on the basis that $12 \%$ of depressed patients (Andrade et al., 2003) fall into a category resembling that corresponding to the definition of TRD employed in our study, the costs in the UK of this part of the depressive spectrum can be estimated to be in the region of $£ 3.9$ billion. In the present study, lost employment and informal care costs were found to account for $54 \%$ of the total, and formal service and treatment costs for only $26 \%$. The dominance of lost employment costs agrees with the findings of previous studies (e.g. Broadhead et al., 1999; Curran et al., 2007; Kessler \& Frank, 1997). The most expensive formal service costs were those for physical inpatient and outpatient care, and GP contacts. Notably, in spite of the evident severity of the condition suffered by this patient group, surprisingly few were admitted to hospital for psychiatric care.

In exploring the variations in costs between individuals, we found that level of functioning was significantly and inversely related to health/social care costs and also to informal care/lost employment costs. The strength of this relationship may have reduced the figure for the impact of depression symptom severity on costs; the latter was 
Running Head: Economic Cost of TRD

statistically significant only for informal care/lost employment. Notwithstanding Given that these latter costs account for the larger fraction of the total costs $s_{2}$, this finding points to the important possibility that treatments whose mode of action aims to directly reduces the level of functional impairment (or, conversely, increases functional capacity) may act-more effectively to-reduce the economic burden of TRD than those thought to act on symptoms more narrowly. Andrews (2001) concluded that the burden of disease attributable to depressive disorders has not fallen in higher-income countries even though evidence-based treatments thought deemed to address mental state symptoms have become more widely available. Likely this will apply particularly in respect ofto TRD patients. Finally, it might seem counter-intuitive that total costs were found to be higher for those who were married/cohabiting. Most likely this reflects the greater availability of informal care for these participants rather than indicating the existence of an intrinsic difference between married/cohabiting patients and those living alone.

\section{Limitations}

Unfortunately, while the GAF is widely used as a proxy of both functioning and symptoms, it has severe limitations as a measure of the many domains involved in functional capacity/impairment (Dimsdale et al., 2010; Smith et al., 2011). In addition to the GAF, we used participant self-report of service use data supplemented by information from medical records. Both sources may not be fully accurate. Recall accuracy can be a problem for self-report data, although studies have shown it to be a reasonable approach (Calsyn et al., 1993; Goldberg et al., 2002). Administrative records may be more accurate for some services (e.g. GP contacts, days in hospital), but may not capture as broad a range of data as self-reporting. 
Running Head: Economic Cost of TRD

A second limitation is that the study was carried out in a particular area of London, albeit one with diverse populations and spanning many socioeconomic conditions, and that the sample consisted of those referred for specialist care. Generalizing the findings to other settings and healthcare systems needs thus to be done cautiously. Given its high costs, this is especially pertinent to inpatient care.

Third, the costs reported included all services used by patients with TRD and not necessarily those used specifically because of TRD. As shown, one in six of the participants accessed services in connection with physical health problems. The existence of complex interactions between depression, physical symptoms, and physical illness is well known. Individuals diagnosed with depression have been found to have higher comorbidity with physical problems and vice versa (e.g. Choi et al., 2014; Smith et al., 2011; Stegmann et al., 2010). However, a $\underline{A}$ matched comparison of groups of non-depressed and depressed non-TRD participants, controlling for physical health/illness, would be required to tease apart the impact of physical and mental health problems.

\section{Conclusion}

In spite ofDespite these limitations, the findings of the present study highlight that severe forms of TRD are associated with high costs, in which unpaid care and lost work predominate. Our findings support the idea that research on treatments that might act on the mechanisms that may exist between impaired levels of functioning and vulnerability to ongoing depression would be particularly valuable. 
Running Head: Economic Cost of TRD

\section{References}

Andrade, L., Caraveo-Anduaga, J. J., Berglund, P., Bijl, R. V., De Graaf, R., Vollebergh, W., . . Wittchen, H. U. (2003). The epidemiology of major depressive episodes: results from the International Consortium of Psychiatric Epidemiology (ICPE) Surveys. International Journal of Methods in Psychiatric Research, 12, 3-21.

Andrews, G. (2001). Should depression be managed as a chronic disease? British Medical Journal, 322, 419-421.

Beck, A. T., Steer, R. A., \& Brown, G. (1996). Manual for the Beck Depression Inventory-II. San Antonio TX: Psychological Corporation.

Beecham, J., \& Knapp, M. (2001). Costing psychiatric interventions. In G. Thornicroft (Ed.), Measuring Mental Health Needs. London: Gaskell.

Berlim, M. T., \& Turecki, G. (2007). What is the meaning of treatment resistant/refractory major depression (TRD)? A systematic review of current randomized trials. European Neuropsychopharmacology, 17, 696-707.

Broadhead, W. E., Blazer, D. G., George, L. K., \& Tse, C. K. (1990). Depression, disability days, and days lost from work in a prospective epidemiologic survey. Journal of the American Medical Association, 264, 2524-2528.

Bromet, E., Andrade, L. H., Hwang, I., Sampson, N. A., Alonso, J., de Girolamo, G., . . . Kessler, R. C. (2011). Cross-national epidemiology of DSM-IV major depressive episode. BMC Medicine, 9:90

Calsyn, R. J., Allen, G., Morse, G. A., Smith, R., \& Tempelhoff, B. (1993). Can you trust self-report data provided by homeless mentally ill individuals? Evaluation Review, 17, 353-366. 
Running Head: Economic Cost of TRD

Choi, S., Lee S., Matejkowski, J. \& Baek, Y.M. (2014).The relationships among depression, physical health conditions and healthcare expenditures for younger and older Americans. Journal of Mental Health, 23, 140-145.

Crown, W. H., Finkelstein, S., Berndt, E. R., Ling, D., Poret, A. W., Rush, A. J., \& Russell, J. M. (2002). The impact of treatment-resistant depression on health care utilization and costs. Journal of Clinical Psychiatry, 63, 963-971.

Curran, C., Knapp, M., McDaid, D., Tómasson, K., \& The Mheen Group (2007) Mental health and employment: An overview of patterns and policies across Western Europe, Journal of Mental Health, 16, 195-209.

Curtis, L. (2011) Unit costs of health and social care. PSSRU, Canterbury.

Demyttenaere, K., Bruffaerts, R., Posada-Villa, J., Gasquet, I., Kovess, V., Lepine, J. P., ... WHO World Mental Health Survey Consortium. (2004). Prevalence, severity, and unmet need for treatment of mental disorders in the World Health Organization World Mental Health Surveys. Journal of the American Medical Association, 291, 2581-2590.

\section{Department of Health (2011) National Schedule of Reference Costs 2009-10. London}

Dimsdale, J. E., Jeste, D. V., \& Patterson, T. L. (2010). Beyond the global assessment of functioning: learning from Virginia Apgar. Psychosomatics, 51, 515-519.

First, M. B., Gibbon, M., Spitzer, R. L., \& Williams, J. B. (2001). User's Guide for the Structured Clinical Interview for DSM-IV-TR Axis I Disorders - research version. New York: Biometric Research, New York State Psychiatric Institute.

Fonagy, P., Rost, F., Carlyle, J. A., McPherson, S., Thomas, R., Fearon, R. M. P., . . . Taylor, D. (2015). Pragmatic randomized controlled trial of long-term psychoanalytic psychotherapy for treatment-resistant depression: the Tavistock Adult Depression Study (TADS). World Psychiatry, 14, 312-321. 
Running Head: Economic Cost of TRD

Fostick, L., Silberman, A., Beckman, M., Spivak, B., \& Amital, D. (2010). The economic impact of depression: resistance or severity? Eurepean Neuropsychopharmacology, 20, 671-675.

Goldberg, R. W., Seybolt, D. C., \& Lehman, A. (2002). Reliable self-report of health service use by individuals with serious mental illness. Psychiatric Services, 53, 879-881.

Greden, J. F. (2001). The burden of disease for treatment-resistant depression. Journal of Clinical Psychiatry, 62 , 26-31.

Hamilton, M. (1967). Development of a rating scale for primary depressive illness. British Journal of Social and Clinical Psychology, 6, 278-296.

Hilsenroth, M. J., Ackerman, S. J., Blagys, M. D., Baumann, B. D., Baity, M. R., Smith, S. R., . . Holdwick, D. J., Jr. (2000). Reliability and validity of DSM-IV axis V. American Journal of Psychiatry, 157, 1858-1863.

Hollinghurst, S., Carroll, F. E., Abel, A., Campbell, J., Garland, A., Jerrom, B., . . . Wiles, N. (2014). Cost-effectiveness of cognitive-behavioural therapy as an adjunct to pharmacotherapy for treatment-resistant depression in primary care: economic evaluation of the CoBalT Trial. British Journal of Psychiatry, 204, 6976.

Ivanova, J. I., Birnbaum, H. G., Kidolezi, Y., Subramanian, G., Khan, S. A., \& Stensland, M. D. (2010). Direct and indirect costs of employees with treatmentresistant and non-treatment-resistant major depressive disorder. Current Medical Research and Opinion, 26, 2475-2484.

Kessler, R. C., Barber, C., Birnbaum, H. G., Frank, R. G., Greenberg, P. E., Rose, R. M., .. W Wang, P. (1999). Depression in the workplace: effects on short-term disability. Health Affairs, 18, 163-171. 
Running Head: Economic Cost of TRD

Kessler, R. C., Berglund, P., Demler, O., Jin, R., Koretz, D., Merikangas, K. R., . . . National Comorbidity Survey Replication. (2003). The epidemiology of major depressive disorder: results from the National Comorbidity Survey Replication (NCS-R). Journal of the American Medical Association, 289, 3095-3105.

Kessler, R. C., \& Frank, R. G. (1997). The impact of psychiatric disorders on work loss days. Psychological Medicine, 27, 861-873.

Kubitz, N., Mehra, M., Potluri, R. C., Garg, N., \& Cossrow, N. (2013). Characterization of treatment resistant depression episodes in a cohort of patients from a US commercial claims database. Plos One, 8(10), e76882.

McCrone, P., Dhanasiri, S., Patel, A., Knapp, M., \& Lawton-Smith, S. (2008). Paying the price. The cost of mental health care in England in 2026. London: King's Fund.

McManus, S., Meltzer, H., Brugha, T., Bebbington, P., \& Jenkins, R. (2009). Adult Psychiatric Morbidity in England, 2007: Results of a Household Survey. National Health Service Information Centre for Health and Social Care, London

Mrazek, D. A., Hornberger, J. C., Altar, C. A., \& Degtiar, I. (2014). A review of the clinical, economic, and societal burden of treatment-resistant depression: 19962013. Psychiatric Services, 65, 977-987.

Office for National Statistics, 2011. Annual Survey of Hours and Earnings, 2010 $\underline{\text { Revised Results. }}$ http://webarchive.nationalarchives.gov.uk/20151013205951/http://www.ons.gov .uk/ons/rel/ashe/annual-survey-of-hours-and-earnings/2010-revisedresults/index.html [accessed 23 October 2017]. 
Running Head: Economic Cost of TRD

Olchanski, N., McInnis Myers, M., Halseth, M., Cyr, P. L., Bockstedt, L., Goss, T. F., \& Howland, R. H. (2013). The economic burden of treatment-resistant depression. Clinical Therapeutics, 35, 512-522.

Richards, D. (2011). Prevalence and clinical course of depression: a review. Clinical Psychological Review, 31, 1117-1125.

Simon, G. E., Goldberg, D. P., Von Korff, M., \& Ustun, T. B. (2002). Understanding cross-national differences in depression prevalence. Psychological Medicine, 32, 585-594.

Smith, G. N., Ehmann, T. S., Flynn, S. W., MacEwan, G. W., Tee, K., Kopala, L. C., . . . Honer, W. G. (2011). The assessment of symptom severity and functional impairment with DSM-IV axis V. Psychiatric Services, 62, 411-417.

Stegmann, M. E., Ormel, J., de Graaf, R., Haro, J. M., de Girolamo, G., Demyttenaere, K., . . Investigators, E. M. (2010). Functional disability as an explanation of the associations between chronic physical conditions and 12-month major depressive episode. Journal of Affective Disorders, 124, 38-44.

Stimpson, N., Agrawal, N., \& Lewis, G. (2002). Randomised controlled trials investigating pharmacological and psychological interventions for treatmentrefractory depression. Systematic review. British Journal of Psychiatry, 181, 284-294.

Taylor, D., Carlyle, J. A., McPherson, S., Rost, F., Thomas, R., \& Fonagy, P. (2012). Tavistock Adult Depression Study (TADS): a randomised controlled trial of psychoanalytic psychotherapy for treatment-resistant/treatment-refractory forms of depression. BMC Psychiatry, 12, 60. 
Running Head: Economic Cost of TRD

Thomas, L., Kessler, D., Campbell, J., Morrison, J., Peters, T. J., Williams, C., . . . Wiles, N. (2013). Prevalence of treatment-resistant depression in primary care: cross-sectional data. British Journal of General Practice, 63(617), e852-858. WHO. (2010). Depression.

http://www.who.int/mental_health/management/depression/definition/en/ (accessed 27.07.16). Retrieved from

http://www.who.int/mental_health/management/depression/definition/en/ 
Table 2

Use and costs of services in 12 months prior to interview (in 2009/10, $£$ )

\begin{tabular}{|c|c|c|c|c|c|c|}
\hline Service & $\begin{array}{l}\text { Number } \\
\text { using } \\
\text { service }\end{array}$ & $\begin{array}{c}\% \\
\text { using } \\
\text { service }\end{array}$ & $\begin{array}{c}\text { Mean } \\
\text { contacts } \\
\text { by users }\end{array}$ & $\begin{array}{c}\text { SD of } \\
\text { contacts }\end{array}$ & $\begin{array}{c}\text { Mean } \\
\text { cost } \\
\text { for } \\
\text { whole } \\
\text { sample }\end{array}$ & $\begin{array}{c}\text { SD of } \\
\text { cost }\end{array}$ \\
\hline Psychiatric inpatient & 4 & 3 & 15.3 & 10.4 & 188 & 1131 \\
\hline Physical inpatient & 20 & 17 & 9.7 & 17.8 & 816 & 3426 \\
\hline Psychiatric outpatient & 11 & 9 & 16.3 & 19.0 & 175 & 872 \\
\hline Physical outpatient & 84 & 71 & 9.2 & 22.1 & 855 & 2804 \\
\hline Psychiatric day hospital & 3 & 3 & 145.3 & 22.0 & 358 & 2255 \\
\hline Physical day hospital & 7 & 6 & 1.9 & 1.2 & 177 & 1321 \\
\hline $\begin{array}{l}\text { Accident and } \\
\text { emergency }\end{array}$ & 34 & 29 & 1.7 & 1.1 & 57 & 111 \\
\hline GP & 119 & 100 & 10.8 & 6.2 & 511 & 405 \\
\hline Practice nurse & 82 & 69 & 3.2 & 3.6 & 18 & 30 \\
\hline District nurse & 2 & 2 & 10.5 & 13.4 & 3 & 26 \\
\hline $\begin{array}{l}\text { Community mental } \\
\text { health treatment }\end{array}$ & 14 & 12 & 6.2 & 13.5 & 23 & 142 \\
\hline Other nurse & 2 & 2 & 10.5 & 13.4 & 4 & 35 \\
\hline Health visitor & 1 & 1 & 1.0 & - & 1 & 6 \\
\hline Counsellor & 51 & 43 & 8.8 & 12.7 & 149 & 369 \\
\hline Psychologist & 28 & 24 & 9.4 & 15.7 & 174 & 684 \\
\hline Psychiatrist & 22 & 18 & 4.7 & 4.5 & 201 & 613 \\
\hline Occupational Therapist & 11 & 9 & 1.7 & 1.2 & 5 & 18 \\
\hline Social worker & 9 & 8 & 3.3 & 4.2 & 22 & 114 \\
\hline Homecare worker & 4 & 3 & 58.5 & 13.0 & 284 & 1901 \\
\hline $\begin{array}{l}\text { Community support } \\
\text { worker }\end{array}$ & 6 & 5 & 16.7 & 18.8 & 23 & 143 \\
\hline Housing worker & 7 & 6 & 3.9 & 3.0 & 9 & 66 \\
\hline Voluntary worker & 4 & 3 & 29.8 & 23.5 & 23 & 150 \\
\hline Day centre & 3 & 3 & 35.2 & 25.4 & 14 & 111 \\
\hline Self-help group & 8 & 7 & 33.0 & 50.4 & 27 & 180 \\
\hline Other therapist & 24 & 20 & 9.0 & 13.9 & 110 & 436 \\
\hline Alternative therapy & 17 & 14 & 22.3 & 62.4 & 59 & 396 \\
\hline Community doctor & 4 & 3 & 12.5 & 13.2 & 28 & 216 \\
\hline Physiotherapist & 8 & 7 & 7.1 & 6.2 & 22 & 107 \\
\hline Dietitian & 1 & 1 & 2.0 & - & 1 & 13 \\
\hline Antidepressants & 99 & 83 & - & - & 51 & 125 \\
\hline Total service costs & - & - & - & - & 4388 & 7347 \\
\hline Informal care & 57 & 48 & 16 & 28 & 5772 & 16053 \\
\hline $\begin{array}{l}\text { Lost employment for } \\
\text { participants }\end{array}$ & 80 & 67 & & & 11964 & 12678 \\
\hline Total indirect costs & & & & & 17736 & 20605 \\
\hline Total cost & & & & & 22124 & 23466 \\
\hline
\end{tabular}


Running Head: Economic Cost of TRD 